\title{
Discursos y antecedentes de los retratos feministas en el arte contemporáneo
}

\author{
Discourses and Antecedents of the Feminist Portraits in Contemporary Art
}

\author{
Gabriela Arhelí García Guerra ${ }^{a}$, Coral Revueltas Valle ${ }^{b}$
}

\begin{abstract}
:
Art has served as a tool to spread different philosophies and thoughts. At the beginning of the 21 st century, feminism uses artistic portrait to make known gender inequality. The present essay contain two sections that explain how feminist thought and artistic portrait collaborate to criticize society. In the first section are mentioned the different approaches to art, the sum of the disciplines with which the works are supported for their conceptualization and the representation of the feminine paradigms. In the second, are mentioned examples of feminist discourses in the portraits for a denunciation to the contemporary world. In the last section, there is a reflection on how art with a critical content has the ability to direct viewers towards an understanding of equity and thereby carry out a cathartic act. On the other hand, the methodology is of a qualitative nature, that is to say, both the works and the theories were selected to sustain the work.
\end{abstract}

Keywords:

Pictoric portrait, female portrait, feminism, art

\section{Resumen:}

$\mathrm{El}$ arte ha servido como herramienta para difundir distintas filosofías y pensamientos. A inicios del siglo XXI, el feminismo utiliza el retrato artístico para dar a conocer la desigualdad de género. En el presente ensayo se abordan dos apartados que explican cómo el pensamiento feminista y el retrato artístico colaboran para hacer una crítica a la sociedad. En el primer apartado, se mencionan los distintos enfoques del arte, la suma de disciplinas con las cuales las obras se apoyan para su conceptualización y la representación de los paradigmas femeninos. En el segundo, se mencionan ejemplos de los discursos feministas en los retratos para una denuncia al mundo contemporáneo. En el último apartado se hace una reflexión sobre cómo el arte con un contenido crítico tiene la capacidad de dirigir a los espectadores hacia un entendimiento de equidad y con ello llevar a cabo un acto catártico. Por otro lado, la metodología es de carácter cualitativo, es decir, tanto las obras como las teorías se seleccionaron para sustentar el trabajo.

Palabras Clave:

Retrato pictórico, retrato femenino, feminismo, arte

\section{Introducción}

Las problemáticas actuales en el retrato artístico radican en la interpretación y sus límites, por lo cual, se busca precisar los alcances de estas obras, es decir, los retratos contemporáneos con un discurso de género tienen como origen diferentes disciplinas. De esta manera, los puntos

\footnotetext{
${ }^{a}$ Mtra. Gabriela Arhelí García Guerra gagabyneta@gmail.com reside en Chihuahua, Chihuahua y es doctoranda en la Universidad Autónoma de Chihuahua.

b Dra. Coral Revueltas Valle coralrevueltas.revueltas@gmail.com profesora de tiempo completo en la Universidad Autónoma de 
de encuentro del arte con otras áreas del conocimiento nos permiten comprender el rol del retrato artístico en la actualidad. Las cuestiones artísticas tienen una naturaleza que se dedica a observar al mundo para representarlo, por lo cual es necesario utilizar y entender otras áreas del conocimiento. Por un lado, la pintura tiene encuentros con reflexiones filosóficas desde su origen, un ejemplo de estos acercamientos lo menciona Pinotti (2011)

Efectivamente, el carácter de la apasionada fijación de Simmel por Rembrandt o la de Merleau-Ponty por Cézanne [...] aquellos filósofos observaron la condensación, en imágenes sobre el lienzo, de su propio pensamiento. Menos exclusivo, aunque no menos intenso, es decir, no menos generador de ideas, la relación que Heidegger establece con Van Gogh, la de Foucault con Magritte o la de Deleuze con Bacon (p. 14).

Asimismo, Mandoki (2006) hace notorio como el arte no sólo tiene aspectos estéticos, sino que además trata "dimensiones políticas, económicas, semióticas y sociales" (p. 218). De esta manera, por medio del arte se engloban diferentes disciplinas las cuales contribuyen a las obras con contenidos conceptuales. Otro ejemplo, sería como por medio del arte se representan eventos históricos, en México, Diego Rivera se dio a la tarea de educar a la población a través de sus murales con cargas políticas e históricas. Según Acha (1993)

El Estado mexicano fue uno de los que tomó conciencia de la utilización de las artes para educar a los miembros de su sociedad dentro de ideales y postulados convenientes. México empezó así a practicar las políticas culturales, un nuevo recurso estatal (p. 217).

De este modo, se mostró brevemente la capacidad del arte de contener una porción de diferentes ramas del conocimiento, tanto cargas filosóficas como de educación. El arte pues, no es una ciencia exacta, ni tiene una utilidad práctica inmediata, sino que sirve para comprender el todo en el cual nos desenvolvemos, canaliza las emociones y ayuda analizar la posición social del espectador. De acuerdo con Villa y Gatica (2018), "la creación se vuelve un acto político" (p. 58). Asimismo, el arte no busca dar datos cuantificables sobre las problemáticas que aborda, sino reflejar las diferentes perspectivas y hacer visible aquello sin forma, no obstante, las aportaciones de sus piezas dejan un precedente de protesta. Por otro lado, según García (2005)

[...] la importancia de las actividades artísticas en la conservación milenaria de una forma de vida, conocimientos y costumbres. En ésta valoración de nuestros antepasados se nota la relación estética con su entorno natural para apreciarlo, protegerlo, aprovecharlo y desarrollarse armónica con él (pp. 89-90). Bajo esta perspectiva, se asume entonces la importancia del arte por cultivar el pensamiento crítico en la sociedad. De tal manera, la historia y sus hechos han quedado plasmados en las obras de arte, lo cual nos da una idea de lo que en la actualidad también se produce. Es decir, las obras precedentes contienen discursos latentes y problemáticas, que en el siglo XXI se abordan con el propósito de combatirlas.

\section{Los paradigmas de la representación femenina}

Desde hace varias décadas se ha hecho evidente que las mujeres tienen menos posibilidades y privilegios dentro de la sociedad, distintos pensadores han hecho teorías al respecto. Por un lado, Bourdieu (1998), menciona que desde una perspectiva simbólica en la cotidianidad, lo sagrado es el parámetro representativo de la mujer, lo cual según el autor es un acto de sometimiento (p. 29). De este modo, los esquemas de pensamiento que rigen a las sociedades generan ideas, costumbres y ritos opresores (p. 31) hacia el género femenino que posteriormente se ven reflejados en el arte. Por otro lado, Butler (2007) sugiere la posibilidad de la disolución de los géneros y por tanto del desequilibrio existente. Es decir, Butler debate sobre ser mujer, sus implicaciones y ataduras, también menciona cómo "La representación es 
la función normativa de un lenguaje que, al parecer, muestra o distorsiona lo que se considera verdadero acerca de la categoría de las mujeres" (p. 46). Ambos autores concuerdan en como la mujer simbólicamente se encuentra deformada. Con lo anterior, me refiero a una concepción de lo femenino subestimada y catalogada en rangos imprecisos. Asimismo, Galarza (2016) agrega a la discusión sobre "El feminismo, como teoría y como práctica política, ha trabajado en la identificación de la violencia explícita, pero también en la que se oculta; ha combatido la violencia simbólica y la material desde los años setenta" (p. 819).

No obstante, las diferencias entre los sexos no sólo se visualizan en lo simbólico, pues de acuerdo con las Guerrilla Girls, un grupo de mujeres artistas dedicadas a denunciar la desigualdad de género a través de carteles -entre otras cosas- con datos duros, dentro de museos como el Met de New York y el Museu de arte de Sao Paulo existe una mínima cantidad de expositoras, pero un gran número de desnudos femeninos en las obras (ver figura 1). De este modo, la agrupación artística hace evidente la cosificación del cuerpo y del poco valor intelectual que se le da a la mujer dentro de los más importantes museos de arte. Asimismo, Giunta (2018) menciona "Recordemos que en 1970 se habían producido protestas contra la escasa representación de artistas mujeres en el Museo Whitney de Nueva York (apenas un 5\%)(sección Arte, feminismo y políticas de representación, párr. 3). Ciertamente, los paradigmas de la representación femenina se encuentran en aspectos desde la apariencia física, la ideología, hasta la brecha salarial y el rezago de producción femenina en los espacios de exhibición artística.

a pesar de todo lo que los estándares tradicionales se han modificado, podemos constatar que desde que nacemos las instituciones nos clasifican en varones y en mujeres, y que las estadísticas dicen que las artistas clasificadas como mujeres representan, en el mejor de los casos, un $30 \%$ de lo que se realiza en el mundo del arte. En ese sentido, y para refinar las problemáticas diferenciaciones, cuando me refiero a "artistas mujeres" en verdad me refiero a aquellxs artistas a quienes la sociedad y sus instituciones clasifican como mujeres, criterio a partir del cual disminuyen su representación. (Giunta, 2018, sección ¿Artistas mujeres?, párr. 2)

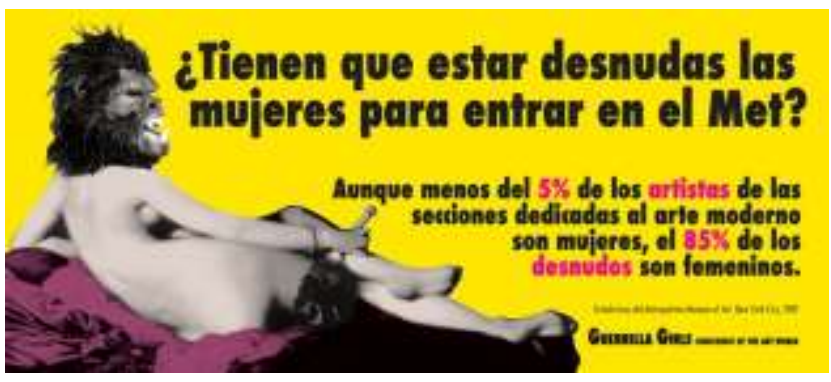

Figura 1. Guerrilla Girls, técnica mixta, 1989. Fuente: https://www.guerrillagirls.com/exhibitions/\#nosoyfeminist a-quito

En la actualidad la mujer, su rol y su representación forman parte de una discusión acerca de sus derechos, prácticas y costumbres. De acuerdo con Berger (1972) los paradigmas femeninos reflejados en el arte consistían en la dependencia de los hombres, asimismo el autor agrega "La presencia social de la mujer se ha desarrollado como resultado de su ingenio para vivir sometida a esa tutela y dentro de tan limitado espacio" (p. 26). En el arte contemporáneo las mujeres han consolidado sus críticas por medio de los discursos de género. Según Giunta (2018) "Para la mujer, relegada al hogar, el arte era un adorno, no una profesión. Y lo que ellas hacían no entraba dentro de los sistemas de reconocimiento del arte serio, con mayúsculas" (sección Las artes visuales y el lugar de la mujer en el arte, párr. 4). Por un lado, la representación de la mujer en el arte se ha transformado, del mismo modo que la figura de la creadora femenina también ha logrado posicionarse en el mundo del arte. De tal manera, es a partir del feminismo cuando se cuestiona la desigualdad. Por otro lado, el retrato en el arte contemporáneo no tiene la necesidad de un rostro, de acuerdo con Rodríguez (2010)

este género siempre exige un punto de verdad, bien sea a través de La indicación del título, bien a través de unos trazos básicos en los que se 
reconocen ojos, boca, nariz, o algún rasgo corporal, bien gracias a alguna referencia particular (p. 56).

Debido a esta apertura en las obras, entran diferentes problemáticas, las cuales involucran los recursos de interpretación del espectador. A través de imágenes se ha visibilizado la problemática, por medio de los rostros de mujeres desaparecidas o que fueron, es el caso del pintor Brian Maguire quien se dedicó durante cuatro años a retratar a estas mujeres víctimas del feminicidio en colaboración con sus familias en Ciudad Juárez (Vulliamy, 2014, párr. 41). De acuerdo con Giunta (2018)

Ante el aumento de víctimas violadas, quemadas o empaladas hasta la muerte, arrojadas como basura en baldíos, y ante la falta de datos oficiales, las ONG desarrollaron algunas estadísticas: un homicidio cada treinta horas, 322 feminicidios en 2016 cometidos por hombres familiares de la víctima, cercanos, que en el 17\% de los casos habían sido previamente denunciados (sección Introducción, párr. 15).

A pesar de las cifras señaladas por Giunta, no es medible el impacto de una obra en la población, mas queda claro que son recordatorios constantes de la lucha en contra del feminicidio y se han encargado de contraponer ideas para confrontar a la sociedad. Los paradigmas femeninos continúan adaptándose a estas ideas de igualdad, sin embargo, es una tarea compleja. "La figura del feminicidio y la violencia hacia los cuerpos y la psique de las mujeres fue tomando un estado público y un grado de generalización sin precedentes" (Giunta, 2018, sección Introducción, párr. 15). Según Mandoki (2006) hay una intoxicación estética, por esta razón hay una normalización de estos hechos con extrema violencia. El rol inferior de la mujer, es la consecuencia de una sociedad caótica, envuelta en un círculo vicioso.

Es cada vez más difícil refutar que muchos de los problemas más graves de la sociedad contemporánea están directa, aunque no exclusivamente, relacionados con la estética. Me refiero a la drogadicción, al racismo, a la criminalidad, al suicidio, el alcoholismo, la violencia doméstica, la pornografía, la obesidad en incluso enfermedades emocionales como la depresión crónica particularmente aguda en países altamente tecnologizados. No están porque las condiciones mínimas para la sobrevivencia física $Y$ mental del ser humano está su dignidad estética. Quien requiere constantemente de estímulo a través de las drogas o alcohol huye de la miseria estética y encía prendimiento que no logro obtener por otras vías. (Mandoki, 2006, pp. 184-185.)

Por esta razón, distintos colectivos, artistas y pensadores se han dado a la tarea de unir fuerzas para una reivindicación social, con este tipo de observaciones y con ello generar cambios de conciencia en el tejido social. Según Rosas (2013) "Conociendo el papel que ha jugado el arte en la construcción del espacio en Ciudad Juárez, podremos comprender como se ha dado este dialogo entre los artistas y la ciudad, y por lo tanto, entre ciudad y sociedad" (p. 60).

\section{La denuncia a través del género del retrato}

Por medio del retrato pictórico es posible la trascendencia de un ser, de este modo Diego Velázquez buscaba con su serie de bufones de la corte, que los modelos fueran reconocidos más allá de sus condiciones físicas o labores reales. De acuerdo con Sánchez (1996) "ese rostro del enano, tristemente contenido, expresa a su vez la superioridad espiritual de este hombre deforme y sencillo sobre el mundo aparentemente tan alto y tan bello que lo rodea" (La pintura como lenguaje, párr. 6). No obstante, este género del arte cuenta con la misma capacidad de reconocer los aspectos negativos de una persona. Es decir, es posible hacer énfasis en lo desagradable, inmoral o incluso aspectos ajenos al control del propio retratado como una enfermedad o una violación. De acuerdo con Rodríguez (2010), Géricault lo hizo con su obra 'Enferma de monomanía' en 1820. No obstante, el retrato feminista tiene se enfoca en denunciar la desigualdad de género y el abuso, además busca 
cuestionar los parámetros de belleza e incluso los rangos de poder. Ciertamente, es posible que algunas obras fueran elaboradas antes de que Simone de Beauvoir introdujera su teoría feminista, sin embargo, pertenecen a esta categoría por la cualidad de su contenido y son tanto antecedentes artísticos como testimonios de dichas experiencias. Es el caso de Artemisa Genrileschi quien utilizó la pintura para exaltar el comportamiento machista de su época tras ella misma haberlo experimentado. De alguna manera, en sus obras deja la huella de su experiencia. Según Pollock (2007) "los primeros cuadros de Artemisia Gentileschi son vehículos de expresión personal hasta un grado extraordinario, podemos rastrear el progreso de su experiencia, como víctima primero de intimidación sexual, y más tarde de violación" (p. 173).

De tal manera, a mediados del siglo $X X$ y principios del XXI distintas artistas se dieron a la tarea de manifestar su impotencia ante las injusticias por medio del retrato feminista. A través de sus obras reflejan la desigualdad de género, pero sobre todo ejercen la posibilidad otorgada por el arte de difundir crímenes de género y con ello reflexionar para cuestionar sobre las prácticas sociales. De acuerdo con Dröes (2006) Marlene Dumas es una artista plástica sudafricana, la cual representa en sus retratos los tópicos principales de discriminación de su país cómo el racismo, la desigualdad de género y los paradigmas religiosos (p. 390). Por otro lado, Olga Guerra (ver figura 2) hizo una convocatoria de víctimas de abuso o acoso sexual con o sin denuncias ante la justicia para llevar a cabo su trabajo con la serie Se busca. Consiguientemente, Guerra hizo públicos los resultados en formato de carteles en las redes sociales y algunos de ellos fueron colocados en espacios públicos. A pesar de que la obra de Guerra no muestra las figuras de mujeres, si expone los rostros de sus acosadores. Con relación a hacer públicas denuncias ciudadanas a través del arte Mónica Mayer tiene obra como El Tendedero y Lo Normal ambas de 1978 y con un discurso en contra de la violencia de género, asimismo Mayer (2009) menciona Si bien la denuncia a través del arte es importante, a veces existe el riesgo de estetizar la violencia 0 de replicarla visualmente provocando una sensación de victimización en el público, lo cual sólo refuerza al sistema. Por eso cada vez me interesan más las obras que tratan de desarticular el sistema evidenciando su estructura o interviniendo en la realidad para cambiarla (p. 202).

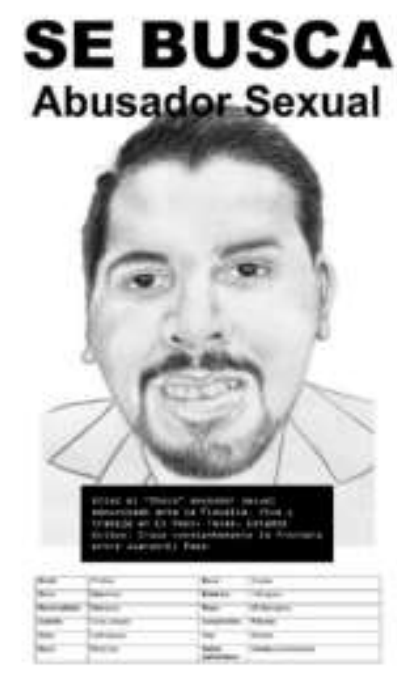

Figura 2. Olga Guerra, técnica mixta, 2017

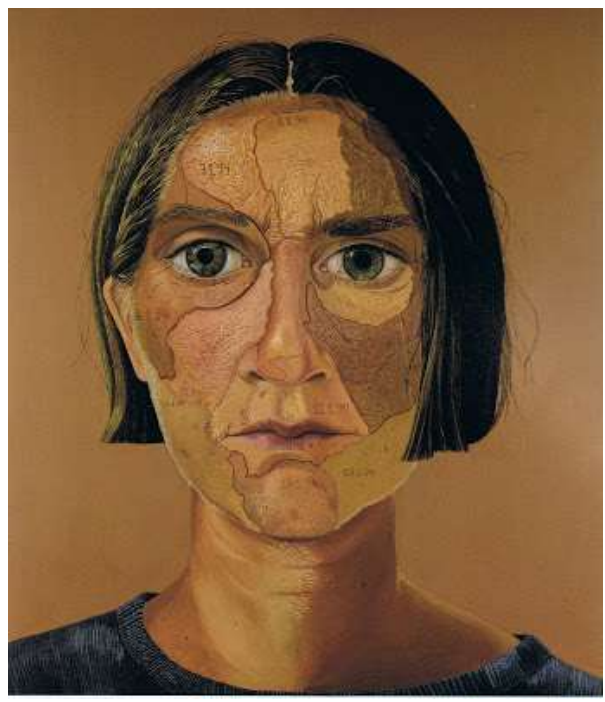

Fig. 3 Mónica Castillo, Autorretrato en tareas. Fuente: http://lucesdete.blogspot.com/2010/09/los-rostros-demonica-castillo.html

De tal manera, los retratos se han ido transformando conforme la concepción del arte de su época, no obstante, a pesar del momento histórico existe constancia por parte de las creadoras en denunciar la misógina o estereotipos femeninos como hace Frida Kahlo con sus autorretratos o su obra Unos cuantos piquetitos. Según Lara (2007) "en California en la escuela 
de arte feminista que fundó Judy Chicago [...] fue un vehículo muy fuerte para darle forma al pensamiento feminista en México o fomentar alianzas femeninas muy fuertes" (p. 418). Por tanto, el retrato hecho por creadoras desde mediados del siglo $X X$ busca representar emociones dolorosas como Paula Rego con la serie del aborto, Ana Mendieta con sus autorretratos fotográficos con los cuales "deconstruye la pureza de las identidades occidentales dominantes" (Blocker, 2007, p. 392). Por otra parte, Jenny Saville propone plasmar la vida de la mujer (Meagher, 2003) y la fase de la maternidad, sin idealizar los cuerpos como una propuesta alternativa a los medios masivos en donde la mujer asume la maternidad sin dificultad y aspira a rangos de belleza occidentales ( $p$. 38). Asimismo, Mónica Castillo refleja en su autorretrato (ver figura 3) su rostro como mapa, en donde las experiencias rebasan las expectativas de vida, es decir, demuestra aquellos recorridos inesperados, luchas y deseos que convierten a los sujetos en seres únicos, su obra desafía la validez otorgada por los cánones de belleza para revalorar las huellas del tiempo sobre el cuerpo como algo irrepetible.

\section{Conclusión}

El retrato representa la ancestral necesidad de permanencia y trascendencia, en él se encuentra el reflejo de lo social y busca que la memoria del ser humano quede plasmada. Por lo cual, el retrato construye un vínculo temporal, el cual tiene el propósito de ser visto y analizado. Según Patrón (2018) "cuando podría parecer que una pieza es exclusivamente subjetiva y que se enfoca en la recuperación de la memoria personal o familiar de su autor los relatos que produce son siempre culturales" (p. 40). De la misma manera, en el retrato se encuentran proyectadas las tradiciones, valores y moral de su época, a pesar de que se concentra en un sujeto particular, su interpretación está sujeta a distintos enfoques. No obstante, el creador detrás de cada obra coloca una carga política o una crítica en su discurso. Las obras, son consecuencia del sistema de vida que llevamos a cabo y del placer innato de crear. Por un lado, la muerte y crímenes de mujeres son el efecto de la cosificación arraigada de la mujer por parte de una sociedad con imposiciones ideológicas occidentales. En el retrato se proyecta lo que está oculto en la sociedad, son las huellas de un daño y se utiliza la creación como válvula de escape. Es decir, el retrato es un género que le dice a la sociedad su absurdo y señala sus defectos.

Los retratos feministas pueden contener los atributos antes mencionados y, además, contar con la aportación de los discursos de género en el arte, estos se comprometen a romper con los paradigmas, ya que son estos los que encasillan el papel de cada ser dentro de la sociedad. De este modo, reflejar en el retrato un mensaje abyecto transgrede el estado de confort del espectador. Respecto a lo anterior, Martínez-Artero (2004) menciona cómo "el retrato contemporáneo plantea interrogantes y cuestiona estereotipos (p. 255)". A pesar de la necesidad de tocar temas actuales, los retratos feministas se cimientan en artistas pasados que revolucionaron su época gracias a la ruptura de los paradigmas, si bien es cierto, que las creadoras a lo largo de la historia no han tenido el mismo apoyo o difusión que los hombres, el feminismo contemporáneo busca romper con el androcentrismo y recuperar el reconocimiento de la obra femenina. Es el caso de Hilma af Klint pionera en el arte abstracto o Sofonisba Anguissola retratista y pintora de la corte, ambas poco reconocidas en la historia del arte. Asimismo, pintoras como Cordelia Urueta y Débora Arango han logrado manifestarse por medio del retrato y representaciones femeninas proponiendo nuevas visiones sobre lo que es el ser mujer y las problemáticas que estas tienen. Asimismo, Marinela de la Hoz y Mónica Castillo, cuestionan los paradigmas femeninos por medio de autorretratos. De tal modo, el retrato feminista es un subgénero en donde se utiliza la teoría y la práctica para proponer con base a las necesidades de su espacio y tiempo, las obras buscan mejorar el tejido social a partir de hacer visible las imposiciones androcéntricas, eurocéntricas y obsoletas. En conclusión, el sentido del arte, de crear y de transgredir las barreras intelectuales 
se obtiene por medio de hacer posible un cambio a través de las imágenes.

\section{Referencias}

[1] Acha, J. (1993). Expresión y apreciación artísticas: artes plásticas. D.F., México: Editorial Trillas.

[2] Berger, J. (2000). Modos de ver. Gustavo Gili

[3] Blocker, J. (2007). Tierra. K. Cordero e I. Sáenz (coompiladoras). Crítica feminista en la teoría e historia del arte (pp. 377-400). D.F., México: CONACULTA.

[4] Bourdieu, P. (1998). La dominación masculina. París, Francia: Editorial Anagrama.

[5] Butler, J. (2007). El género en disputa: El feminismo y la subversión de la identidad. Ediciones Paidos Ibérica, New York.

[6] Dröes, F. (2006). Art at the edge: The painter Marlene Dumas. Feminist Theology, 14(3), 389-397. DOI: 10.1177/0966735006063776.

[7] Galarza Fernández, E., Cobo Bedía, R., y Esquembre Cerdá, M. (2016). Medios y violencia simbólica contra las mujeres. Revista Latina de Comunicación Social. DOI: 10.4185/RLCS-2016-1122.

[8] García, A. (2005). Enseñanza y aprendizaje en la educación artística Teaching and Learning in Artistic Education, 80-97.

[8] Giunta, A. (2018). Feminismo y arte latinoamericano: historias de artistas que emanciparon el cuerpo. Buenos Aires, Argentina: Siglo veintiuno editores.

[9] Lara, M. (2007). La memoria es como una piedra pulida. K. Cordero e I. Sáenz (coompiladoras). Crítica feminista en la teoría e historia del arte (pp. 415-420). D.F., México: CONACULTA.

[10] Mandoki, K. (2006). Prácticas estéticas e identidades sociales: Prosaica II. Tlanepantla, México: conaculta.

[11] Mandoki, K. (2008). Estética cotidiana y juegos de la cultura: Prosaica l. D.F., México: Conaculta.

[12] Martínez-Artero, R. (2004). El retrato: Del sujeto en el retrato. Montesinos.

[13] Mayer, M. (2009). Un breve testimonio sobre los ires y venires del arte feminista en México durante la última década del siglo XX y la primera del XXI. Debate Feminista, 40, 191-206.

[14] Meagher, M. (2003). Jenny Saville and a feminist aesthetics of disgust Hypatia, 18(4), 23-41. DOI:10.1353/hyp.2003.0085.

[15] Patrón, M. (2018). El libro-arte en México en el siglo XXI como dispositivo de resistencia social. M. Achig (Coord.). El arte de la edición y la tipografía (pp. 39-50). (1st ed.). Ciudad Juárez, México: Universidad Autónoma de Ciudad Juárez.

[16] Pinotti, A. (2011). Estética de la pintura. Madrid, España: Machado Libros.

[17] Pollock, G. (2007). La heroína y la creación de un canon feminista: Las representaciones de Artemisa Gentileschi de Susana a Judit. K. Cordero e I. Sáenz (coompiladoras). Crítica feminista en la teoría e historia del arte (pp. 161-196). D.F., México: CONACULTA.

[18] Rodríguez, I. (2010). El retrato contemporáneo. Del realismo a la pérdida del rostro. Revista de Estética y Arte Contemporáneo, 2, 46-57.
[19] Rosas, C. (2013). La reivindicación de la ciudad por el arte urbano: Ciudad Juárez, Chihuahua, México. Arte y Ciudad, 3, 59-70.

[20] Sánchez, A. (1996). Cuestiones estéticas y artísticas contemporáneas. Fondo de Cultura Económica.

[21] Villa, F. y Gatica, A. (2018). Libros para la memoria: Creación colectiva de libros-arte en pueblos originarios de México. M. Achig (Coord.). El arte de la edición y la tipografía (pp. 51-59) (1st ed.). Ciudad Juárez, México: Universidad Autónoma de Ciudad Juárez.

[22] Vulliamy, E. (2014). Painted back to life: Brian Maguire's portraits of the victims of Mexico's "feminocidio"| The Guardian. Retrieved $\begin{array}{llll}\text { February } 24, & \text { 2019, from }\end{array}$ https://www.theguardian.com/artanddesign/2014/may/04/brianmaguire-portraits-victims-mexico-feminocidio-ciudad-juarez. 